\title{
POTENTIAL OF MODAL SHIFT AND PARK AND RIDE SCHEME AT BRT PESHAWAR
}

\author{
${ }^{\text {a} E n g r . ~ T a l h a ~ H a r o o n ~ K h a n, ~ a ~ D r . ~ S a m e e r ~ U d-D i n, ~ a ̂ E n g r . ~ M a l i k ~ S a q i b ~ M a h m o o d, ~}$ \\ ${ }^{b}$ Dr. Jawed Iqbal, ${ }^{\mathrm{c}}$ Engr. Nasir Ali \\ a'Department of Transportation Engineering, School of Civil and Environmental Engineering, \\ National University of Sciences and Technology, Islamabad 44000, Pakistan. \\ ${ }^{b}$ NUST College of Civil Engineering, Risalpur, \\ National University of Sciences and Technology, Risalpur Campus, Pakistan. \\ ${ }^{c}$ Universtia degli Studi di Palermo, Palermo, Italy \\ DOI: https://doi.org/10.51193/IJETSI.2021.6302
}

\begin{abstract}
Bus Rapid Transit (BRT) is considered as a vital component of a transportation system. It offers a lower investment cost, flexible implementation and a more advanced land system. Moreover, Park and Ride scheme along with BRT offers an efficient solution to modern-day traffic complications with a proficient urban infrastructure and a robust economy. This study evaluated the potential of modal shift from private vehicles to BRT and Park and Ride scheme at BRT Peshawar. Multinomial regression was used to assess the data obtained by the Stated Preference (SP) survey. Socioeconomic characteristics, trip and parking characteristics were the three main areas that were considered regarding public transport users. In the results, it was observed that travel time, out of vehicle travel time and travel cost along with some socioeconomic factors including age, education, and income level affect the mode choice and parking usage. Similarly, the study revealed that middle-class people are more likely to utilize the facility. Furthermore, the modal shift and parking usage can be augmented by providing subsidies, improving the level of service and implementation of policies that restrain car usage.
\end{abstract}

Keywords: Bus Rapid Transit, Multinomial Regression, Modal Shift, Park and Ride Scheme, Parking Estimation, Stated Preference Survey

\section{INTRODUCTION}




\section{International Journal of Engineering Technology and Scientific Innovation}

ISSN: 2456-1851

Volume: 06, Issue: 03 "May-June 2021"

Transportation is inextricably linked with economic development, social progress and the qualitative life of an urban system.[1] For improving these parameters, the road infrastructure of a city always needs to be planned for the betterment of all aspects of a system.[2] One of the major components of the urban transportation system is passengers that have increased throughout the world over the past few decades due to an increase in the population, urban migration and an increase in economic activities. Subsequently, this has increased the ridership in the cities whereas the current system is incapable of holding the increased volumes of passengers.[3] The existing transport system has caused unnecessary delays, salvage costs, high energy consumption and more specifically has augmented RTA's due to its poor condition.[4]

In Pakistan, the traffic system modifications are desperately needed to make daily travel easier and faster. The former system has lost the capability to handle the emerging traffic mass. Peshawar, the capital of Khyber Pakhtunkhwa, comprising of about $1275 \mathrm{~km}^{2}$ and a population of 2,133,000 is experiencing the same grim situation of growing traffic. With increasing economic activities and uncontrollable population growth, efficient mobility in the city has become problematic. The traffic system in the city is highly heterogeneous consisting of a wide variety of traffic e.g. private vehicles, taxis, rickshaws, buses, wagons, motorcycles and cycles. People usually preferred buses and wagons as a cheaper mean of commuting but urbanization in the near past has shifted the mode towards private vehicles. Furthermore, due to an increase in wealth profile, cars and motorcycles have become affordable and passengers are preferring private vehicles over public vehicles for increased mobility, safety, time-saving and comfort purposes.[5] Moreover, people are also reluctant to travel via public transport due to status issues.[6] Regarding the public transport, buses and wagons are operating at a speed of $11 \mathrm{~km} / \mathrm{hr}$ which is far below than $25 \mathrm{~km} / \mathrm{hr}$ (standard operating speed for public transport).[7] The reason for this reduction of speed is the difficulty of large vehicles to maneuver through congested traffic. Whereas taxis were charging double fares and people were not preferring this mode as well.[8] Thus, all these issues have caused a high passenger car and motorcycle share. For this high volume of traffic, there are no parking facilities which have promoted curb-side parking and hence led to the congestion.[9] The existing highly congested traffic has deteriorated air quality, increased noise and vibrations and emission of maximum toxic gases.[10] This is an alarming situation for the city's public transport.

Therefore, an improved system with a dedicated bus lane and special parking lots was inevitable to save the time and money of the citizens. Hence, Bus Rapid Transit (BRT) systems have gained worldwide popularity as a cost-effective alternative and best solution to address all the aforementioned issues.[2,11,12] It will reduce the accidents, congestion, fuel consumption and emission of toxic gases in the city.[13,14] This study aims to find the probable modal shift of private vehicles (cars and motorcycles) users to BRT and the potential of Park and Ride Scheme 
International Journal of Engineering Technology and Scientific Innovation

ISSN: 2456-1851

Volume: 06, Issue: 03 "May-June 2021"

at BRT. It is based on the stated preference (SP) approach for developing modal split models to predict the choices of passenger car users and motorcycle users to use BRT. The parking spaces have been estimated for the commutersintending to utilize Park and Ride facility.

The paper has been examined as follows;

Section 2 conscripted the review of previous studies regarding modal shift and parking analysis, whereas section 3 describes research objectives and methodology. Furthermore, Section 4 presents model results and discussions. In the end, section 5 presents applications of the developed models and conclusions are presented in section 6.

\section{LITERATURE REVIEW}

It has been a concern of every government to get people shifted from personal vehicles to public transport. The out of date transport systems are a threat to the economies and environments of the societies. Currently, people are not willing to shift from their private vehicles towards public transport because the existing public transport systems are deprived of the basic desires people are expecting. After a series of studies, it has been determined thatBus Rapid Transit is the best probable solution to the prevailing traffic conditions. Bus Rapid Transit is worldly adopted as a fruitful measure for urbanized areas to provide people with an efficient and safe mode of transportation.

In previous studies, it has been observed that the modal shift from personal vehicles to BRT occurs as BRT gains comparatively more advantages than private vehicles. This advantage may be in the form of cost, capacity, flexibility, safety, comfort, and reliability. The improvement of these factors is key to attract more commuters out of their vehicles.[4] Moreover, the mode choice also depends upon the socio-economic characteristics of the commuters and the purpose of the trip. The shift from personal vehicles is associated with system performance, personal perceptions, and local circumstances.[15] Access time and operational conditions of public transport have also affected the mode choice.[1] The growing population, land development, congestion, and the associated pollution has convinced people to shift towards public transport and hence BRT. Similarly, scheduleflexibility and cycle time of buses have convinced people on the selection of public transport (BRT) for travel purposes.[16] Moreover, it was found that in developing countries apart from travel time and travel cost, age, gender, education, car ownership, household size, income level and distance from home to public transport also influence the individual's mode choice. However, the reduction of out of vehicle travel time (OVTT) increases the modal share of public transport.[17] The people at the walking distance from the facility mostly preferred this mode than to use their private vehicles.[10] Likewise, people usually preferred to access the terminal station than to transfer stations. Moreover, 
improving the quality of the environment around stations encourages and attracts more passengers.[18] The feeder services provided along the BRT route have provided a pick and drop option for the users and the walking distance was reduced which has increased the daily ridership of buses.[19]

Currently, in Asian developing countries, cars' and motorcycles' share is maximum due to its convenience. Therefore, an improved public transport system with exclusive and priority lanes needs to be developed on high-density corridors or on the routes where the existing system is serving poorly.[6] Similarly, access for bicyclists, motorcyclists and car users' along with their parking spaces needs to be considered. Motorcyclists and bicyclists preferred public transport where there was a subsidized fare.[20] It was observed that frequent stop and go public transport service needs to be revised to mitigate congestion issues in the city. Also, the public transport should be non-signalized or automated vehicle identification should be used to make it a nonstop service.[16]

Moreover, different policy actions are required to reduce car usage i.e. taxes for entering the cities or hubs and arrangements to increase operational costs of private vehicles inside the city. Similarly, increasing the procurement amount of vehicles has increased bus ridership.[9] In the same way, some other measures have also been taken to restrict the usage of personal vehicles and force people to travel via public transport i.e. BRT. It included taxes for entering the city, increased fare for parking at parking spaces and heavy fines for parking at non-authorized spaces.[21] One of the probable solutions is to develop integrated policies and generate circumstances for the new services to be deployed (Park and Ride, congestion charging policy and demand-responsive services, etc.). The main objective of these policies is to create an impact on traffic behavior to attain a modal shift towards more sophisticated and energy-efficient modes e.g. BRT, cycling, and walking, etc.[10] The best approach to modal split is to pose it as a consumer choice and utilize logit models to explain it.[1] Additionally, public transport accessibility, employment ratio, and walking distances affect the calculations of a transportation model.[19] It has been suggested that personal vehicle users should be addressed in such studies to find the modal shift from private cars and motorcycles towards BRT.[15] A study conducted in Jakarta, Indonesia, found that the modal shift towards BRT from personal vehicles in its first month of operation was 20\%.[22] The shift from privatecars to BRT in Los Angeles was $18 \%$ [23] and $12.4 \%$ in Beijing.[24]

With the growing private car ownership, a major concern for authorities is the provision of parking lots in the city hubs to decrease on-street parking and traffic volume on the roads. Decision-makers are confused regarding the locations of parking because of the non- availability of space inside the hubs. Since parking is a basic need for transportation infrastructure but in the 
International Journal of Engineering Technology and Scientific Innovation

ISSN: 2456-1851

Volume: 06, Issue: 03 "May-June 2021"

current promptly emerging urban traffic, the environment is getting worse with the nonprovision of parking spaces. Car owners park their vehicles on the roadside due to the absence of parking lots which causes traffic blockage. This disordered parking causes inconvenience to the daily travelers and influences the living standards of residents.[25] It is vital to minimize traffic congestions, accidents and pollution through proper parking management. Park and ride scheme is an efficient service that may address the aforementioned issues and attract more riders who may not have otherwise opted for public transport. It will provide parking spaces which will reduce the parking needs in the city center. The attractiveness and effectiveness of the park and ride rest on the location of parking, service quality, parking charges, and on-site facilities.[26]

In a private vehicle dominated society, people are not willing to shift towards public transport. Hence, a multimodal transport system needs to be devised where there is a usage of both private vehicles and public transport. A park and ride scheme can fulfill this requirementto park cars and travel via public transport for the remaining journey. Similarly, for reducing long term congestion, solely relying on public transport will be ineffective rather park andride schemes can be a solution to this. It has been observed that for encouraging parking atthe park and ride station, the fare should be minimal or even preferably free.[27] Likewise, it has been found that the reduction in car usage can be achieved if limited parking spaces are available. The parking spaces should neither be very close to a city hub nor at a very far distance.[28] Parking demand is also affected by vehicle ownership, trip rate, parking duration, fuel price, and road pricing.[29] Usually, more parking means more autos and henceless transit. But that is the case when parking is provided at the destination. Conversely, if the parking is near to the origin of commuting trips and the preferred mode to access BRT station is the automobile, an increase in the transit ridership can be expected.[30] These parking facilities will attract varying amounts of new traffic and will consequently change the traffic distribution and circulation patterns in the study area, depending on their locations andsurplus capacities.[20]. Similarly, along with the park and ride for cars, cycle park and ride can attract passengers as well.[31]

In the past ridership was estimated using cross-classification and trip rate analysis but nowadays, multiple regression models are widely used for estimating modal shift, ridership, and parking demands. They are time-saving, simple to use and easy to interpret. Similarly, regression analysis has an advantage over past methods that it addresses the particular station under observation while past methods were applied over large transport zones. Regression models better estimate the impacts of the station environment on travel demand. The four- step model was fed with costly mobility surveys while regression models require ridership data from a single station.[32] Regression analysis was also used to interpret the commuter's behavior in the selection of station to be approached for the trip and it was revealed thatyoung commuters 
walk farther to access a rapid rail transit station.[18]

To conclude, parking is an essential part of the overall transportation and land development system. BRT can be an efficient solution to modern-day traffic complications but with the provision of proper parking spaces, the system can be upgraded at its utmost level. It will be an advantage to the developers for land-use efficiency, urban designing, and a robust economy. Likewise, balanced parking ensures boosted business activities, good aesthetics, and a proficient urban infrastructure.

\section{OBJECTIVES AND METHODOLOGY}

\subsection{Objectives}

This study aimed at achieving the following objectives:

- To find the modal shift of passengers from private vehicles (car and motorcycles) to BRT.

- To identify the parking zones and estimating parking spaces for Park and RideScheme at BRT Peshawar.

\subsection{Data Collection}

The survey was conducted at 16 stations out of 31 stations. These stations were chosen based on their locations which cover a wider population catchment comprising mainly various types of residential areas expected to propel users to use BRT.[28] These stations are located in a suburban area and only the suburban area is provided with parking facilities at the BRT stations. These stations have a provision of adequate parking space, which cater to the parking demand and the parking area is not linked to other land use categories.[33]

The data was collected using the revealed preference approach (RP) and stated preference approach (SP). RP part questioned the current travel behavior and its perspectives while the SP part was regarding the future system and their expectations. Passengers were interviewed individually and the questionnaire form was filled. The survey comprised a total of 31 questions which enclosed three major information regarding the passenger: personal details or socioeconomic characteristics, travel characteristics and parking characteristics. The individual's age, gender, education, income level, and vehicle ownership were enquired in personal details. In travel characteristics, the individual's origin, destination, travel time, travel cost and their will to shift towards BRT were enquired. In parking characteristics, passenger's opinion was taken regarding the parking location, facilities they are expecting, will they park their vehicles or not, 
an estimated amount of parking fare and the walking distance they are willing to cover from parking to BRT station. The survey was conducted at both peaks (morning and evening) and off-peak hours. Similarly, data was collected on working days and weekends as well. A total of 498 passengers responded to the survey. Sincethe concern was the shift of the private vehicle owners (passenger cars (PC) and motorcyclists (MC)) to the BRT, therefore, only vehicle owners were selected and theremaining responses were obliterated. Out of the total respondents, 433 were vehicle owners.

\subsection{Sample Details}

The age groups in the data are mentioned in Figure 1. Similarly, gender distribution is shown in Figure 2. Moreover, each commuter was asked about his trip purpose and his behavior towards BRT for the same trips. The purpose wise ridership has been shown in Figure 3. Similarly, their willingness for out of vehicle travel time was also interrogated and has been presented in Figure 4.

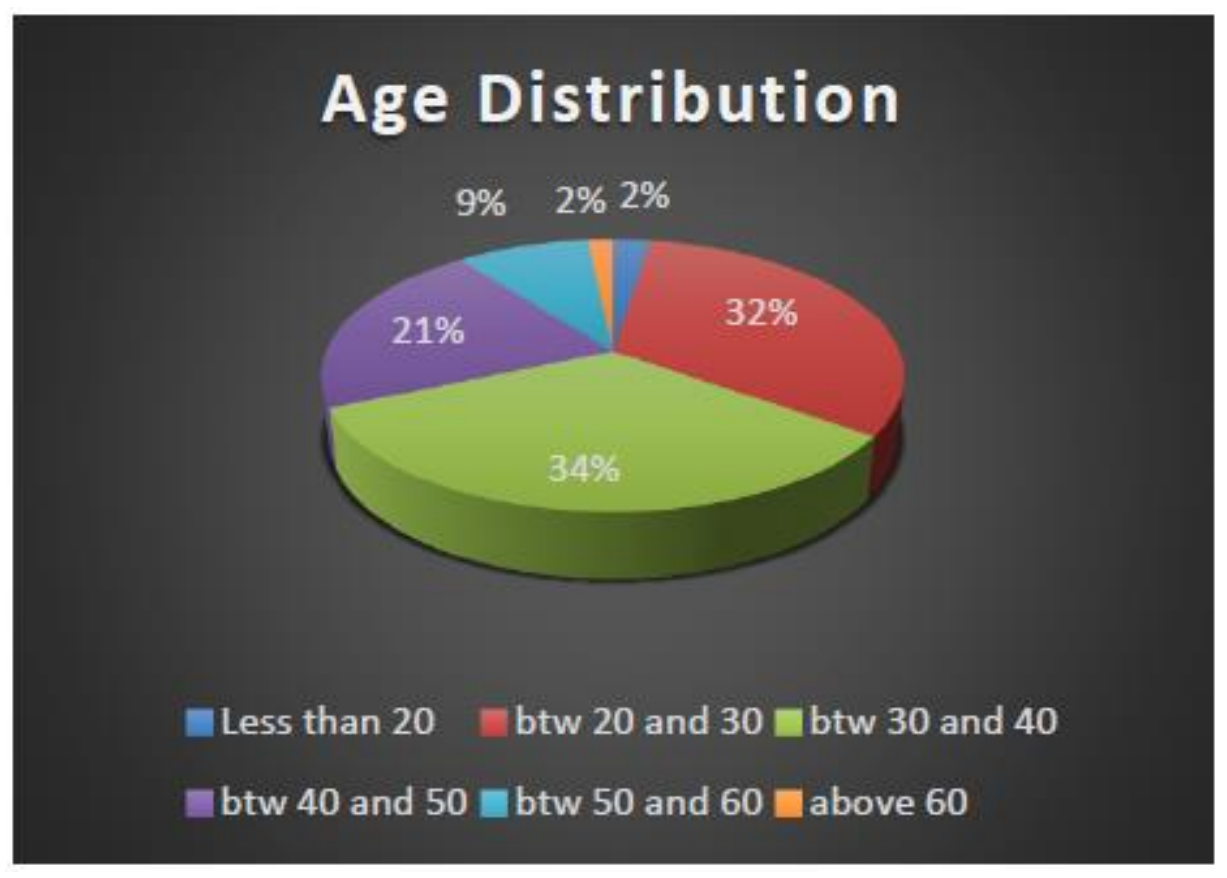

Figure 1: Age Distribution 


\section{Gender Distribution}

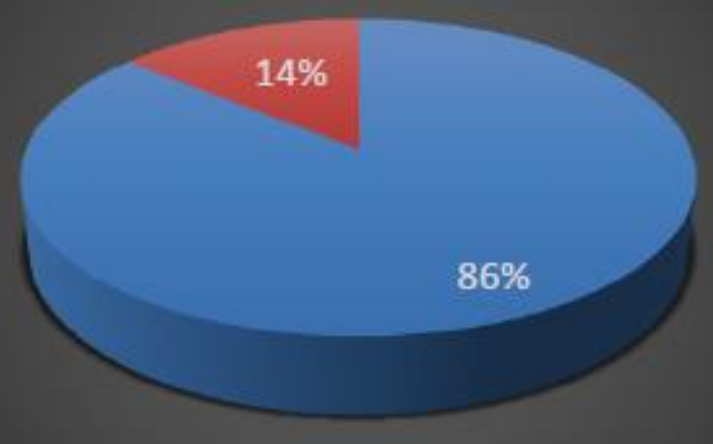

Male Female

Figure 2: Gender Distribution

\section{Ratio of purpose wise ridership on BRT}

$4 \%$

\section{$12 \%$}

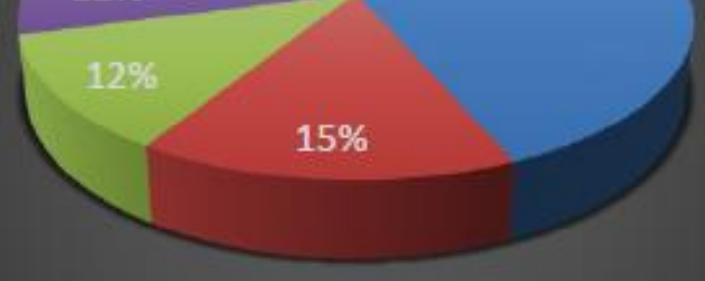

Work

Education

nOthers
Shopping

Recreation

Not willing to travel on BRT

Figure 3: Ridership on BRT on the basis of purpose 


\section{Distance from Station to Parking}

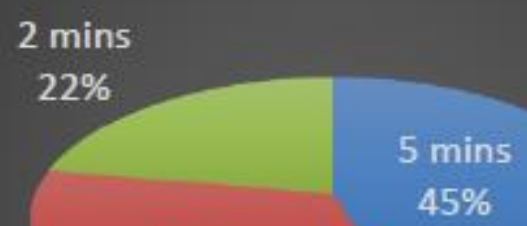

10 mins

$33 \%$

a 5 mins $\quad 10$ mins $\quad 2$ mins

Figure 4: Willingness of OVTT

The education level of respondents was grade 13. The average income of car owners per month was PKR. 37253 whereas for motorcyclists it was a bit lower i.e. PKR. 28967.

\subsection{Model Development}

\section{Modal Shift Analysis}

The model is based on utility theory which assumes that commuters opt for the mode which maximizes their utility. The multinomial logit model has been used in this study for estimating the modal shift from private vehicles to BRT.

The utilities at the respective station have been found using:

$$
\Delta \mathrm{U}=\ln \left(\frac{1-P_{B R T}}{P_{B R T}}\right)
$$

Where,

$\Delta \mathrm{U}=$ change in the utility from the existing system towards BRT. 
$\mathrm{P}_{\mathrm{BRT}}=$ probability of $\mathrm{BRT}$ (percent of the people opting for BRT)

Using the above equation, utility at each station was estimated whereas PBRT was obtained from the survey. For estimating the modal shift, change in travel time and travel cost of trips at each station were used. Travel time of BRT was estimated using the speed at which the buses will run i.e. $40 \mathrm{~km} / \mathrm{hr}$. Similarly, travel cost was calculated using the fares given by the consultants Mott Mac Donald Pakistan (MMP). Travel time and travel costs of the current system were obtained from the SP survey.

Change in travel time was used i.e.

$\Delta$ Time $=\left(\right.$ Travel Time $\left.e_{\text {current system }}\right)-\left(\right.$ Travel Time $\left.{ }_{\text {BRT }}\right)$.

Similarly, change in cost was used i.e.

$\Delta$ Cost $=($ Travel Cost current system $)-\left(\right.$ Travel Cost $\left.{ }_{\text {BRT }}\right)$.

Along with these two variables, three more variables age, education, and income level of individuals at the relevant stations were also used to estimate the modal shift. These weretaken as average as per survey findings.

Now regression analysis was performed in excel by setting $\Delta \mathrm{U}$ as dependent variable and $\Delta \mathrm{T}$, $\Delta \mathrm{C}$, age, education, and income level as independent variables.

Obtaining $\Delta \mathrm{U}$ from regression analysis and putting in:

$$
\mathrm{P}_{B R T}=\frac{e^{\Delta \mathrm{U}}}{\left(1+e^{\Delta \mathrm{U}}\right)}
$$

The probable shift from personal vehicles (PC and $\mathrm{MC}$ ) to BRT was obtained.

\section{Parking Analysis}

The utilities for a shift with the availability of parking spaces at concerned stations were estimated. For this analysis, those commuters who were vehicle owners and not willing to travel via BRT were also excluded. It comprised 43 respondents and the remaining 390 were used for parking analysis. Similarly, parking time and parking fare were also added in the BRT travel time and fare respectively in this analysis. Parking fare was taken as average fromparking fares (willing to pay) responded by respondents in the survey. Another variable OVTT was also 
introduced in this analysis i.e. the distance people were willing to walk from parking to BRT station. The utilities obtained for the respective stations were put as dependent variable and $\Delta \mathrm{T}$, $\Delta \mathrm{C}$, age, education, income level, and walking distance as independent variables in excel for regression analysis. Obtaining $\Delta \mathrm{U}$ from regression analysisand putting in:

$$
\mathrm{P}_{B R T(\text { parking })}=\frac{e^{\Delta \mathrm{U}(\text { parking })}}{\left(1+e^{\Delta \mathrm{U}(\text { parking })}\right)}
$$

The average of the commuters who were willing to park their vehicles was obtained out of the commuters who were willing to shift from private vehicles to BRT. Since the above-made analysis was for both cars and motorcycles. Motorcycles users (MC) were analyzed separately to obtain an exact parking estimate for motorcycles.

\section{Parking Analysis for Motorcycles}

In this analysis, those commuters were assessed who were motorcycle owners and willing to shift their mode of travel. The procedure was the same with just the exclusion of car users. It changed the variables accordingly and change in utilities for the parking of motorcycles was calculated. Regression analysis was performed with $\Delta \mathrm{U}$ as the dependent variable and $\Delta \mathrm{T}$, $\Delta \mathrm{C}$, age, education, income level, and walking distance as independent variables. Obtaining $\Delta \mathrm{U}$ from regression analysis and putting in:

$$
\mathrm{P}_{B R T(\text { bikes parking })}=\frac{e^{\Delta \mathrm{U}(\text { bikes parking })}}{\left(1+e^{\Delta \mathrm{U}(\text { bikes parking })}\right)}
$$

From this, we determined the percentage of motorcyclists willing to park their motorcycles. It concluded that $24 \%$ out of $15 \%$ of parking users were motorcyclists.

\subsection{Model Validation}

The validation was done by comparing the results with the study made by MMP. Since they have designed three park and ride stations on the BRT with two at both ends and one in the middle of the route adjoining the city hub i.e. Dabgari Garden. The same station was selected for the validation purpose in this study where 128 parking spaces were obtained for carswhile they (consultant) obtained 126 parking lots.

The R-square values for modal shift analysis, parking analysis of private vehicles (cars and motorcycles) and parking analysis of motorcycles are $.82, .83$, and .82 respectively. R-square 
values for a transportation model analysis is acceptable above .8.[34] Another study suggests that the $\mathrm{R}$-square value of .70 is acceptable in the transportation model with five to six variables.[35]

Another test is the p-value and t-stat which shows the dependence of the dependent variable on independent variables. An absolute value of 1.96 or greater of t-stat and 0.05 or less of p-value implies that all presented co-efficient in the model are significant at a 95\% confidence level. In the first two models, all variables are fulfilling the criteria except $\Delta \mathrm{T}$. Similarly, in the last model $\Delta \mathrm{C}$ was not fulfilling the criteria. The previous studies in this regard suggest that a single variable not satisfying the criteria is acceptable and it doesn't affect the model's confidence level.[36]

\section{RESULTS AND DISCUSSION}

\subsection{Results of Model Development}

The equations developed from the models are presented in Table 1.

Table 1: Equations Developed From Models

\begin{tabular}{|l|l|l|}
\hline Users & Multinomial Logit Models & R-square \\
\hline $\begin{array}{l}\text { Modal Shift } \\
(\mathrm{PC} \text { and MC) }\end{array}$ & $\begin{array}{l}\Delta \mathrm{UBRT}=1.66+0.008(\Delta \mathrm{T})+0.015(\Delta \mathrm{C})-0.055(\text { age })-0.116 \\
(\text { education })+1.022 \mathrm{E}-05(\text { income level })\end{array}$ & 0.82 \\
\hline $\begin{array}{l}\text { Parking }(\mathrm{PC} \\
\text { and MC) }\end{array}$ & $\begin{array}{l}\Delta \mathrm{U} \text { parking }=3.465+0.013(\Delta \mathrm{T})+0.0045(\Delta \mathrm{C})-0.078(\text { age })- \\
0.172 \\
\text { (education) }+1.06 \mathrm{E}-05(\text { income level })-0.048(\text { walking distance) })\end{array}$ & 0.83 \\
\hline $\begin{array}{l}\text { Parking } \\
(\mathrm{MC})\end{array}$ & $\begin{array}{l}\Delta \mathrm{U} \text { bike parking }=0.65+0.033(\Delta \mathrm{T})+0.006(\Delta \mathrm{C})- \\
0.027(\text { age })-0.036(\text { education })-1.28 \mathrm{E}-05(\text { income level })-\end{array}$ & 0.82 \\
0.037 (walking distance) & \\
\hline
\end{tabular}

A 13 percent shift was observed from private vehicles to BRT in which 15 percent exhibited their interest in BRT parking lots. Out of this 15 percent, 76 percent are car users and remaining are motorcycles users.

\subsection{Discussion}

1. It is evident from the model that for the modal shift, the co-efficient of change in travel time and travel costs are positive. The preference of travelers will increase with decreasing travel time. Similarly, with decreasing BRT fare, the preference is increasing which shows passengers are expecting a rapid and good quality service with a reasonable 
International Journal of Engineering Technology and Scientific Innovation

ISSN: 2456-1851

Volume: 06, Issue: 03 "May-June 2021"

ticket price.

Regarding the parking analysis of cars and motorcycles, the preference for parking increases with reducing parking time. The co-efficient of change in the cost of overall parking is positive indicating that decreasing parking fare increases the preference. Likewise, the preference increases for motorcycles by decreasing the cost of parking.

2. The sign of co-efficient of age for modal shift and parking analysis both is negative which means with increasing age, the BRT and parking preferences are decreasing. Since younger commuters have no private vehicles so they want to shift towards an efficient public transport system rather than an obsolete system. Whereas, older passengers mostly prefer their private vehicles to get rid of waiting, access and egress times in public transport systems.

3. The sign of co-efficient of education indicates that an educated person is less likely to prefer BRT and parking because of status issues.

4. The sign of co-efficient of income level for modal shift indicates that with increasing income level, the preference of BRT is increasing. Mostly, lower-class people are motorcycle owners and prefer it instead of BRT to save their time. On the other hand, the middle class prefers BRT until their income level is less than PKR.80000 per month. It is because of the affordability issues since running private vehicles is expensive as compared to BRT. Achieving a certain income level, they feel easier and comfortable with private vehicles as it is affordable for them.

As far as the parking is concerned, with an increasing economic level overall parking preference increases because they can afford and want to park their vehicles somewhere. While it decreases for motorcycles parking as they usually don't prefer parking to avoid the parking fee. Given the BRT fare and parking charges, the motorcyclists are reluctant to park their vehicles.

5. The preference for overall parking and motorcycles parking decreases with an increasing walking distance. People usually don't prefer to walk to stations for more than 7 to 8 minutes.

\subsection{Parking Estimation}

For computing the parking spaces that are required to be built at the corresponding station, the ridership data was obtained from the report prepared by the consultants for designpurposes. The product of ridership and percentage of people who (will shift from private vehicles to BRT and) will park their vehicles as well, was calculated to obtain overall parking demand. Now, the parking demand for cars was obtained by multiplying overall parking demand (15\%) with cars percentage i.e. $76 \%$ while the remaining $24 \%$ were motorcycles parking. To cope with land availability issues, multi-storied parking can be considered a solution. The calculations are 
International Journal of Engineering Technology and Scientific Innovation

ISSN: 2456-1851

Volume: 06, Issue: 03 "May-June 2021"

presented in the Table 2: Parking Estimation.

Table 2: Parking Estimation

\begin{tabular}{|c|c|c|c|c|c|}
\hline Stations & $\begin{array}{c}\text { P }_{\text {BRT }} \\
\text { parking }\end{array}$ & $\begin{array}{l}\text { Demand as per } \\
\text { model for PC } \\
\text { and MC }\end{array}$ & $\begin{array}{l}\text { Demand as } \\
\text { per model } \\
\text { for } \mathrm{PC}\end{array}$ & $\begin{array}{l}\text { Demand as } \\
\text { per model } \\
\text { for MC }\end{array}$ & $\begin{array}{c}\text { Parking Spaces } \\
\text { required to be } \\
\text { built }\end{array}$ \\
\hline Haji camp & 0.16 & 454 & 342 & 112 & 364 \\
\hline Gulbahar & 0.16 & 268 & 207 & 61 & 219 \\
\hline Firdous & 0.15 & 215 & 171 & 44 & 180 \\
\hline Shuba Bazar & 0.13 & 83 & 64 & 19 & 68 \\
\hline Dabgari Garden & 0.14 & 170 & 128 & 42 & 136 \\
\hline Saddar & 0.16 & 291 & 224 & 67 & 237 \\
\hline Aman Chowk & 0.15 & 231 & 177 & 54 & 188 \\
\hline Tehkal & 0.17 & 195 & 147 & 48 & 157 \\
\hline Abdara Road & 0.15 & 173 & 131 & 42 & 139 \\
\hline Town & 0.16 & 262 & 204 & 58 & 216 \\
\hline Peshawar University & 0.14 & 331 & 248 & 83 & 265 \\
\hline Board & 0.14 & 291 & 217 & 74 & 232 \\
\hline Phase 3 & 0.16 & 186 & 138 & 48 & 148 \\
\hline Tatara Park & 0.15 & 75 & 57 & 18 & 61 \\
\hline PDA Hayatabad & 0.15 & 58 & 45 & 13 & 48 \\
\hline Karkhano & 0.14 & 236 & 189 & 47 & 198 \\
\hline
\end{tabular}

\section{APPLICATIONS OF DEVELOPED MODELS}

The developed models can be used to determine the modal shift for different scenarios regarding travel time and travel cost of BRT. Similarly, the shift can be transformed by reducing the travel time of BRT by reducing egress and access time, increasing the frequency of buses and bus priority measures. Up-gradation and facilitation of BRT at par with the private vehicles will attract more middle class. The provision of subsidy can attract lower class commuters as that more feasible and economical to them. The provision of different parking facilities for different age groups and gender may magnetize more people to BRT. Further, special provisions for disabled and older commuters to reduce their waiting timescan attract more users. Moreover, decreasing the utility of private vehicles by increasing travel costs, direct road pricing, the increased fare for parking at authorized parking spaces and heavy fines at un-authorized spaces can increase the shift. Similarly, increasing the purchasing cost of vehicles, tax on entering the 
city and congestion tax, reducing speed limits may also enhance modal shift. Also, the provision of parking lots near to stations for reducing out of vehicle travel time and feeder service for reducing door to door travel time can be an efficient method to increase modal shift. Parking promotional initiatives e.g. free Sunday parking, subsidy on BRT parking and awareness programs may boost the shift. Besides these, information technology and employment of different applications to provide real-time information about parking availability and automatic ticketing system for decreasing time wastage may bring dramatic changes in the modal shift from private to BRT vehicles. Finally, the provision of extra facilities e.g. canteen, rest area, mechanic shop, security, proper staff, and special places for women may enhance the modal shift.

\section{CONCLUSION}

This paper examined the potential of the shift from private vehicles to BRT and the potential of parking for commuters. Stated Preference Approach was used to survey passenger car and motorcycle users. The Multinomial Logit Model was used to find the probable shift from private vehicles to BRT and the parking spaces required at selected stations. The results obtained were compared with the results of MMP for validation. Travel time and cost were the two variables that displayed the interest of the middle class and the unwillingness of the lower and upper class for BRT. The travel time can be reduced by improving egress, access services, increasing service frequency and advanced parking system with an automatic ticketing system. Moreover, the modal shift can be transformed into BRT by taking initiatives such as increasing car purchasing cost, direct road pricing, and ushering facilities for agedand disabled people. Similarly, multistoried parking can be considered to cope with the shortage of land space. These provisions would alleviate the congestion issues in the city by reducing car volume on the roads. To conclude, the BRT system should provide a decrease in travel time, a reasonable fare for low and medium-income people, well-designed park andride stations, feeder services and effective policies to restraint vehicle usage with proper awareness programs.

\section{ACKNOWLEDGEMENTS}

Talha defined the topic, set the method, accomplished literature review, conducted the survey, prepared the data, performed the analysis, formulated the model and wrote the manuscript; Sameer defined the topic, set the method and helped in manuscript editing; Jawed and Nasir set the method and helped in model formulation, manuscript editing and submission.

\section{REFERENCES}

[1] H. S. Sathish, "Travel Delay and Modal Split Analysis - A Case Study," IOSR J.Mech. Civ. Eng., vol. 5, no. 2, pp. 40-45, 2013. 
International Journal of Engineering Technology and Scientific Innovation

ISSN: 2456-1851

Volume: 06, Issue: 03 "May-June 2021"

[2] L. Wright, W. H.-I. for T. and D. Policy, and undefined 2007, "Bus rapid transitplanning guide."

[3] P. V. Venkatachalam THAMIZH ARTISAN, "Modelling Modal Shift from Personal Vehicles to Bus on Introduction of Bus Priority Measure," Transport, vol. 1, no. 3, pp. 288-302, 2011.

[4] P. Vedagiri and V. T. Arasan, "Estimating modal shift of car travelers to bus on the introduction of the bus priority system," Jiaotong Yunshu Xitong Gongcheng Yu Xinxi/J. Transp. Syst. Eng. Inf. Technol., vol. 9, no. 6, pp. 120-129, 2009.

[5] A. Khan and M. A. Arshad, "Study of Various Mass Transit Options for Peshawar Cityby Life Cycle Cost Analysis," 1st Int. Multi-Disciplinary Conf. (IMDC), Univ. Lahore, no. December 2017.

[6] T. Satiennam, S. Jaensirisak, W. Satiennam, and S. Detdamrong, "Potential for the modal shift by passenger car and motorcycle users towards Bus Rapid Transit (BRT) in an Asian developing city," IATSS Res., vol. 39, no. 2, pp. 121-129, 2016.

[7] G. D. Ghulam Dastagir, "The Study of Bus Rapid Transit (BRT) System at University Road Peshawar, Pakistan,” IOSR J. Mech. Civ. Eng., vol. 6, no. 5, pp. 75-82, 2013.

[8] A. R. L. Francisco, "Peshawar BRT Preliminary Design Report," J. Chem. Inf. Model., vol. 53, no. 9, pp. 1689-1699, 2013.

[9] S. Sabar and G. A. Anjum, "Problems and Prospects of Curbside Parking in Lahore: PolicyImplications for Effective Management," Mehran Univ. Res. J. Eng. Technol., vol. 36, no. 4, pp. 867-880, 2017.

[10] M. Matulin, I. Bošnjak, and L. Šimunovič, "Different approaches to the modal split calculation in urban areas," Conf. Proc. ICTS 2009 Transp. Marit. Logistics. Sci., pp.1-7, 2009.

[11] D. A. Hensher, "Sustainable public transport systems: Moving towards a value formoney and network-based approach and away from blind commitment," Transp. Policy, vol. 14, no. 1, pp. 98-102, Jan. 2007.

[12] H. Levinson, S. Zimmerman, J. Clinger, S. R.-U. S. T. R., and undefined 2003, "Transit cooperative research program report 90 volume 1: case studies in bus rapid transit."

[13] T. Satiennam, P. Tankasem, W. Satiennam, P. J.-P. of the E., and undefined 2013, "A potential study of Bus Rapid Transit (BRT) supporting low carbon Asian developing city."

[14] H. Kikuchi, A. Fukuda, T. Ishizaka, H. I.-P. of the, and undefined 2013, "Possibility to Realiza Low Carbon City In Medium-sized City of Asia: Case Study in Khon Kaen City, Thailand," researchgate.net.

[15] S. McDonnell, S. Ferreira, and F. Convery, "Impact of Bus Priority Attribute on Catchment Area Residents in Dublin, Ireland," J. Public Transp., vol. 9, no. 3, pp.137- 
International Journal of Engineering Technology and Scientific Innovation

ISSN: 2456-1851

Volume: 06, Issue: 03 "May-June 2021"

162, Jul. 2006.

[16] J. Jarzab, J. Lightbody, and E. Maeda, "Characteristics of Bus Rapid Transit Projects:An Overview," J. Public Transp., vol. 5, no. 2, pp. 31-46, 2002.

[17] A. Nurdden, R. A. O. K. Rahmat, and A. Ismail, "Effect of transportation policies on the modal shift from private car to public transport in Malaysia," J. Appl. Sci., vol. 7, no. 7, pp. 1013-1018, Apr. 2007.

[18] J. Zhao and W. Deng, "Relationship of walk access distance to rapid rail transit stations with personal characteristics and station context," J. Urban Plan. Dev., vol.139, no. 4, pp. 311-321, 2013.

[19] N. Zenina and A. Borisov, "Regression Analysis for Transport Trip Generation Evaluation,” Inf. Technol. Manag. Sci., vol. 16, no. 1, pp. 89-94, 2014.

[20] L. Wung and B. Kindra, "An Innovative Technique for Estimating Trip Generation for Parking Facilities," ITE J., vol. 62, no. 4, 1992.

[21] P. D. Authority, "Environmental Impact Assessment: Peshawar Sustainable Bus Rapid Transit Corridor Project," no. 48289, 2017.

[22] J. P. Ernst, "Initiating Bus Rapid Transit in Jakarta, Indonesia," Transp. Res. Rec. J. Transp. Res. Board, vol. 1903, no. 1, pp. 20-26, Jan. 2005.

[23] L. Callaghan and W. Vincent, "Preliminary Evaluation of Metro Orange Line Bus Rapid Transit Project,” Transp. Res. Rec. J. Transp. Res. Board, vol. 2034, no. 1, pp.37-44, Jan. 2007.

[24] T. Deng and J. D. Nelson, "The perception of Bus Rapid Transit: A passenger survey from Beijing Southern Axis BRT Line 1," Transp. Plan. Technol., vol. 35, no. 2, pp. 201-219, Mar. 2012.

[25] Y. L. Wang, X. Wang, and M. C. Zhang, "Current Situation and Analysis of Parking Problem in Beijing," Procedia Eng., vol. 137, pp. 777-785, 2016.

[26] U. A. Khalid and Kadar Hamsa Abdul Azeez, "Parking utilization pattern of Park and Ride facility at public transportation terminals," Proc. East. Asia Soc. Transp. Stud., vol. 9, no. 2011, p. 16, 2013.

[27] N. Abdul Hamid, J. Mohamad, and M. R. Karim, "Travel behavior of the Park and Ride users and the factors influencing the demand for the use of the Park and Ride facility," EASTS Int. Symp. Sustain. Transp. Inc. Malaysian Univ. Transp. Res. Forum Conf. 2008, vol. 2008, no. August, pp. 1-13, 2008.

[28] A. A. Kadar Hamsa, S. A. A. Syed Adnan, and U. A. Khalid, "Analysis of parking usage at the park and ride facility in Klang valley, Malaysia," WIT Trans. Built Environ., vol. 138, pp. 179-193, 2014.

[29] P. W. Ho, S. M. Ghadiri, and P. Rajagopal, "Future Parking Demand at Rail Stations in Klang Valley,” MATEC Web Conf., vol. 103, pp. 1-9, 2017. 
International Journal of Engineering Technology and Scientific Innovation

ISSN: 2456-1851

Volume: 06, Issue: 03 "May-June 2021"

[30] D. Merriman, "How many parking spaces does it take to create one additional transit passenger?," Reg. Sci. Urban Econ., vol. 28, no. 5, pp. 565-584, 1998.

[31] J. Zhao, W. Deng, Y. Song, and Y. Zhu, "What influences Metro station ridership in China? Insights from Nanjing," Cities, vol. 35, pp. 114-124, 2013.

[32] O. D. Cardozo, J. C. García-Palomares, and J. Gutiérrez, "Application of geographically weighted regression to the direct forecasting of transit ridership at station-level," Appl. Geogr., vol. 34, pp. 548-558, 2012.

[33] C. P. Ng and D. M. Ma'Soem, "The Development Of Model Estimation To Determine Parking Needs At LRT Stations In Suburban Area," Proc. East. Asia Soc. Transp. Stud., vol. 5, pp. 877-890, 2005.

[34] K. P. Liu, Chang, Mark Mangalotti, "DEVELOPMENT OF PREDICTION MODELFOR REAL-TIME PARKING AVAILABILITY FOR ON-STREET PAID PARKING,” Acta Univ. Agric. Silvic. Mendelianae Brun., vol. 16, no. 2, pp. 39-55, 2015.

[35] K. Sohn and H. Shim, "Factors generating boardings at Metro stations in the Seoul metropolitan area," Cities, vol. 27, no. 5, pp. 358-368, 2010.

[36] V. S. Kothapalli, "The use of statistics and its analysis in resolving transportation-related problems related problems," 2014. 